\title{
EDA-EMERGE: an FP7 initial training network to equip the next generation of young scientists with the skills to address the complexity of environmental contamination with emerging pollutants
}

Werner Brack ${ }^{1 *}$, Selvan Govender ${ }^{1}$, Tobias Schulze ${ }^{1}$, Martin Krauss ${ }^{1}$, Meng Hu ${ }^{1}$, Melis Muz ${ }^{1}$, Juliane Hollender ${ }^{2}$, Kristin Schirmer², Jennifer Schollee ${ }^{2}$, Anita Hidasi ${ }^{2}$, Jaroslav Slobodnik ${ }^{3}$, Zuzana Rabova ${ }^{3}$, Selim Ait-Aissa ${ }^{4}$, Manoj Sonavane ${ }^{4}$, Mario Carere ${ }^{5}$, Marja Lamoree ${ }^{6}$, Pim Leonards ${ }^{6}$, Sara Tufi ${ }^{6}$, Xiyu Ouyang $^{6}$, Merijn Schriks ${ }^{7}$, Kevin Thomas ${ }^{8}$, Ana Catarina de Almeida ${ }^{8}$, Jean Froment ${ }^{8}$, Monika Hammers-Wirtz ${ }^{9}$, Marijan Ahel ${ }^{10}$, Sanja Koprivica ${ }^{10}$, Henner Hollert ${ }^{11}$, Thomas-Benjamin Seiler ${ }^{11}$, Carolina Di Paolo ${ }^{11}$, Andrew Tindall ${ }^{12}$ and Petra Spirhanzlova ${ }^{12}$

\begin{abstract}
The initial training network consortium novel tools in effect-directed analysis to support the identification and monitoring of emerging toxicants on a European scale (EDA-EMERGE) was formed in response to the seventh EU framework program call to train a new generation of young scientists (13 PhD fellows and 1 postdoctoral fellow) in the interdisciplinary techniques required to meet the major challenges in the monitoring, assessment, and management of toxic pollution in European river basins. This 4-year project is of particular relevance considering the multidisciplinary analytical chemistry and biology skills required to investigate the enormous complexity of contamination, effects, and cause-effect relationships. By integrating innovative mode-of-action-based biodiagnostic tools including in vitro and in vivo tests, transgenic organisms, and 'omics' techniques with powerful fractionation and cutting edge, analytical, and computational structure elucidation tools, powerful new EDA approaches are being developed for the identification of toxicants in European surface and drinking waters. Innovative method development by young researchers at major European universities, research centers, and private companies has been closely interlinked with a joint European demonstration program, higher-tier EDA, and specialized training courses and secondments. Using a simplified protocol based on existing EDA tools, EDA-EMERGE fellows are also being trained to organize and run international and interdisciplinary sampling and monitoring campaigns within selected European river basin sites. Strong networking between academia, the private sector, and leading regulators in the field of river basin management and pollution management ensures the relevance of the research for practice and excellent employment opportunities for the fellows. Additionally, an internationally composed advisory board has been tasked to introduce new perspectives on monitoring, assessment, and management of emerging pollutants within and outside of Europe. The combination of cutting edge science with specialized training in (Continued on next page)
\end{abstract}

\footnotetext{
* Correspondence: werner.brack@ufz.de

'UFZ Department of Effect-Directed Analysis, Helmholtz Centre for Environmental Research, Permoserstr. 15, Leipzig 04318, Germany Full list of author information is available at the end of the article
} 
(Continued from previous page)

complimentary soft skills is being offered with a strong emphasis on commercial exploitation and media competence which further enhances the employability of the fellows in research, academia, and beyond.

Keywords: Effect directed analysis; Emerging chemical pollutants; EU river basins; Bio-assays; Analytical chemistry; EDA-EMERGE

\section{Background}

Water quality in many European rivers improved significantly over the last 30 years, and river waters exhibiting acute lethality to fish or invertebrates are an exception today. However, toxic pressure by pesticides [1], biocides [2], endocrine disruptors $[3,4]$ and many other chemicals [5] still presents a large-scale risk and causes community shifts and the disappearance of sensitive species in many river basins. The European Water Framework Directive (WFD) [6] provides a new holistic approach for the assessment and management of the ecological status of water bodies. However, the WFD chemical monitoring and classification is still centered on the traditional approach of regulating individual chemicals, the priority substances (PS) and the river basin specific pollutants, via compliance with environmental quality standards. This approach, based on chemical analysis of single substances, cannot cover the enormous variety of potentially hazardous chemicals present in the environment, which occur in complex and time variable mixtures. Subsequently, the observation of adverse effects in biota is often not reflected by the occurrence and concentrations of PS but caused by other non-regulated contaminants of emerging concern. In a discussion paper by Christian Daughton, US Environmental Protection Agency (USEPA) stated that 'an ever-expanding universe of unique chemicals, untold numbers of which have yet to be recognized or revealed, continually perfuse our environment and contact living systems' [7]. In 2005, 26 million individual chemical substances were identified and registered in the Chemical Abstract Service (http://www.cas. org/), with one-third being commercially available [7]. By June 2013, this number had increased to 72 million. The continuous increase in the diversity of chemicals being used makes identifying those that occur in our environment an increasingly difficult task. The screening of environmental samples, such as extracts of water, sediments, or biota, with liquid or gas chromatography coupled with high-resolution mass spectrometry (LCHRMS) typically reveals tens of thousands of peaks, the majority of which are unknown.

Nationally and across the member states, there is an increasing awareness that the analysis of PS alone is insufficient to characterize the toxic pressure to aquatic ecosystems and water resources [8,9]. In response, powerful new screening methods are being developed.
These include multi-target analyte approaches together with suspect screening, e.g., the use of transformation prediction models to propose transformation products without available standards and the screening of unknowns including all detected masses or peaks [10]. However, the identification of unknowns, particularly with LC-MS techniques, is very challenging and timeconsuming and therefore unlikely to be available as a routine technology for all chemicals in the complex mixtures that are found in the environment. Approaches are required to focus analytical efforts on those chemicals that actually pose a risk or cause an effect. Two of the most prominent methodologies to approach this challenge, effect-directed analysis (Figure 1) and toxicity identification evaluation, apply biological tools to select fractions of a mixture and individual components for identification and structure elucidation efforts according to measurable effects [11-15].

Significant methodological development in EDA has been achieved within the last years as reflected by a recent book on this topic [16]. However, significant bottlenecks remain which are now being addressed by the Marie Curie initial training network (ITN) project, EDAEMERGE. Research within EDA-EMERGE is directed towards developing powerful new bio-analytical detection tools to significantly improve the analytical power of LC-HRMS-based structure elucidation by interlinking with novel, powerful computer tools, to enhance EDA throughput, and to reduce sample requirements and the risk of artifacts by means of miniaturization and automated online combination of fractionation, biotesting, and chemical analysis. The most important aspect of EDA-EMERGE, however, is its people. This ITN has been designed to produce a new generation of experts that are trained during their $\mathrm{PhD}$ studies in biological and chemical tools and the attendant integration in order to unravel and assess complex contamination of the aquatic environment for the sustainable management of European water resources in close collaboration with key players in WFD implementation such as the European Commission Joint Research Centre (JRC), the European Environmental Agency, and the German Federal Environmental Agency.

The EDA-EMERGE consortium includes two universities (Free University of Amsterdam and the RWTH Aachen University), six research centers (Helmholtz 


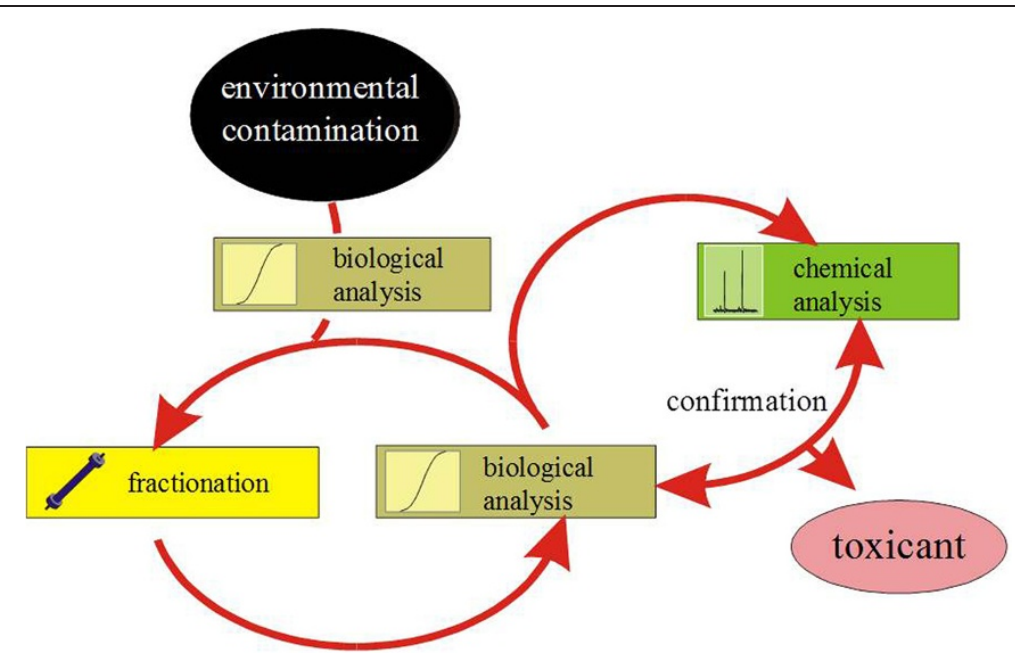

Figure 1 Schematic representation of effect-directed analysis.

Centre for Environmental Research (UFZ), Institut National de l'Environment Industriel et des Risques (INERIS), Swiss Federal Institute of Aquatic Science and Technology (Eawag), Rudjer Boskovic Institute, Norwegian Institute for Water research, the Italian Institute of Health, the JRC), and five private companies (Environmental Institute, KWR Watercycle Research Institute, WatchFrog, HighChem, and gaiac) (Figure 2). EDA-EMERGE is an outcome of the European Network of Reference Laboratories for Monitoring of Emerging Environmental Pollutants (NORMAN) and strongly benefits from this platform, bringing together 55 partners from science, monitoring, and regulation in 19 countries [17]. Since complex contamination is not exclusively a European problem, EDA-EMERGE is also networking with renowned overseas partners such as advisors from the US-EPA and Environment Canada.

\section{Novel scientific tools}

On the basis of the outstanding expertise of their host institutes in EDA, the $13 \mathrm{PhD}$ fellows are developing novel methods for advanced EDA in three work packages, viz. bio-analytical tools, chemical tools, and hyphenated tools. A specific focus of bio-analytical tool development will be on vertebrate in vivo and in vitro models for genotoxicity, mutagenicity [18] and AhRmediated toxicity, and for endocrine disruption [19]. This will include innovative transgenic models using multi-well-based fluorescent screens for androgenic and corticosteroid disruptors on the basis of extensive experience with tadpole fluorescent screens for thyroid hormone disruptors (Figure 3) and fluorescent zebrafish transgenic embryos for estrogens [20].

Existing EDA approaches are limited by the lack of knowledge and availability of toxicological endpoints to direct toxicity isolation and identification. This limitation is addressed by EDA-EMERGE with the investigation of toxicogenomic tools to detect and unravel toxicants with unknown receptors and modes of action. The new approaches include DNA microarray fingerprints in algae [21,22], a proteomic approach in zebrafish embryos previously established in adult fish tissue [23] to direct EDA, and a metabolomics EDA approach using invertebrate and fish cell lines in vitro.

Together with the detection of adverse effects, the identification and structure elucidation of components of toxic fractions are a bottleneck in EDA, particularly of polar compounds requiring LC-MS analysis. Tool development focuses particularly on LC-HRMS methods that have successfully been applied by EDA-EMERGE partners for the identification and quantification of glucocorticoid compounds [24], drugs [25], and other polar micropollutants [26]. EDA-EMERGE combines the analytical power of HRMS with computer tools to predict fragmentation, chromatographic retention, and stability $[27,28]$. Mass spectra of newly identified compounds will feed the community-driven, open-access, accurate mass spectral database MassBank [29] maintained by NORMAN. Significant enhancement of the throughput of EDA towards more routine application will be achieved by automated approaches to directly link fractionation, biotesting and identification [30].

\section{European demonstration program}

Applying a simplified EDA protocol featuring a novel on-site large-volume solid phase extraction apparatus with limited fractionation, a selected set of bioassays and chemical screening analysis will be used to characterize about 20 sites within European river basins. This approach combines sites of interest according to sources of 


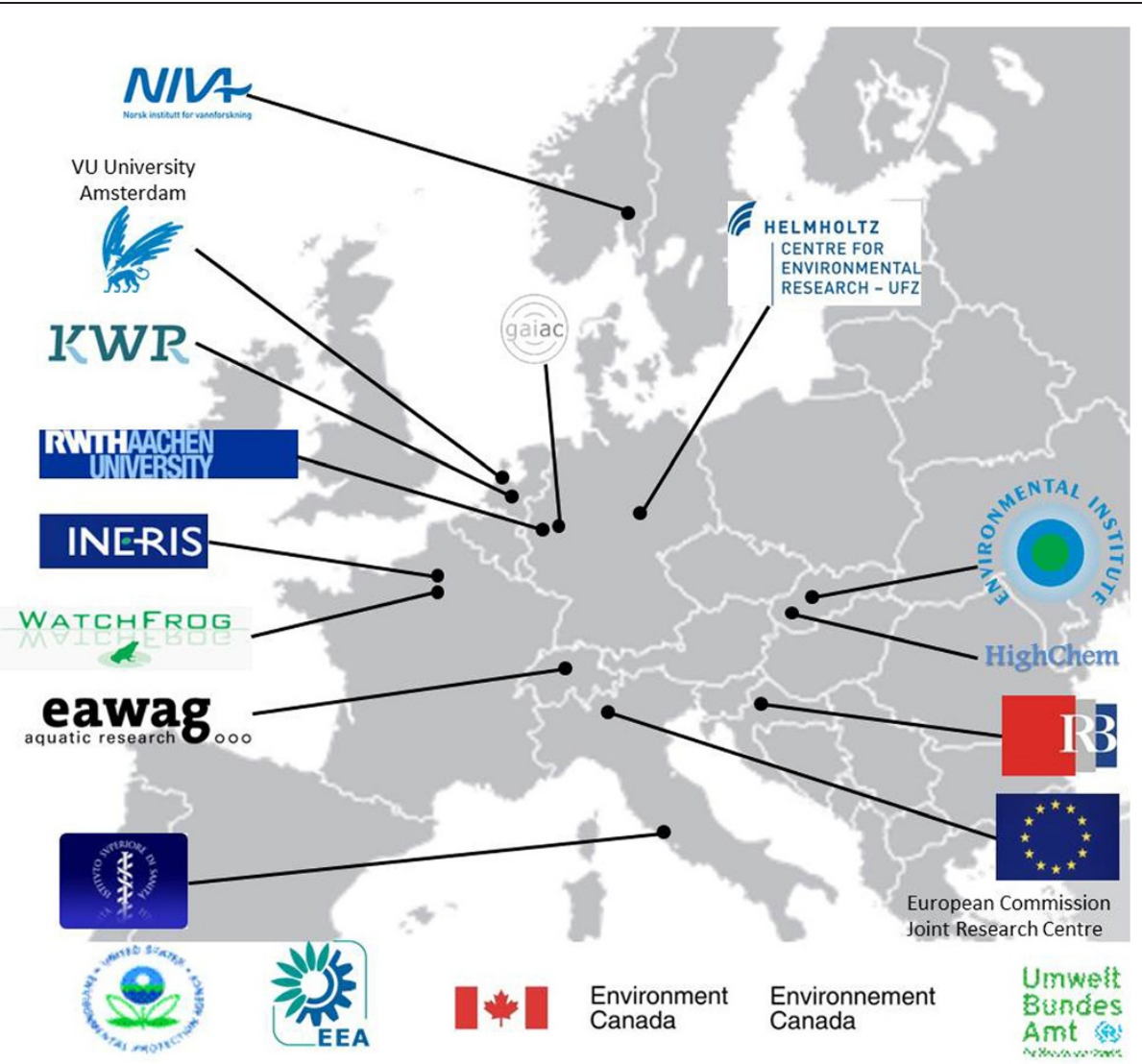

Figure 2 Geographical spread of the EDA-EMERGE consortium.

contamination such as municipal wastewater, treated hospital effluents, industrial sites affecting water quality, untreated wastewater entering the river, and reference sites with European sampling stations downstream of impacted headwaters. The European Demonstration Program will allow a comparison of classical monitoring approaches with the new tools and will train the $\mathrm{PhD}$ fellows in organizing and running common sampling campaigns on a European scale.

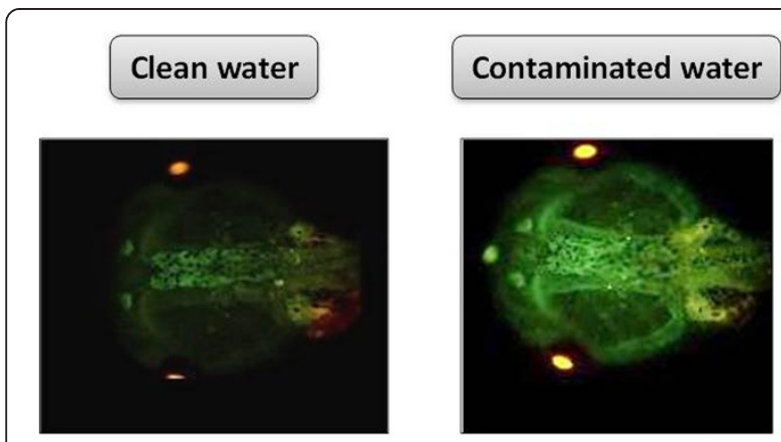

Figure 3 Response of transgenic Xenopus laevis tadpoles to endocrine disruptors in water.

\section{Training program}

In line with the major objective of equipping young interdisciplinary researchers with the skills to address the challenges of complex contamination and its effects on aquatic ecosystems and to support WFD implementation, an extensive training program was set up and was enthusiastically followed by the $\mathrm{PhD}$ fellows. Although having a primary focus on EDA-EMERGE PhD students, the courses are open to external participants within the attendant maximum capacity, and this opportunity has been intensively utilized by $\mathrm{PhD}$ fellows from across Europe.

The formal training program kicked off with a week-long summer school (25 to 29 June 2012). The PhD fellows were lectured by leading scientists within the EDA-EMERGE consortium and beyond on the European regulatory framework, EDA, sampling and sample preparation, separation and fractionation, biodiagnostic tools, and chemical analysis. Additionally, there was also a PC-based workshop on structure elucidation along with virtual case studies. The scientific program was supplemented with a half day excursion to Wechselburg in Saxony where fellows and lecturers learnt about the river Mulde, a previously heavily 
contaminated river in a now scenic, tourist-friendly setting, which is slowly recovering (Figure 4). This also provided an informal and relaxed atmosphere for intensive and fruitful networking that significantly promoted EDA-EMERGE progress.

The summer school was followed by several specialized training courses including a course on advanced LC-MS and multivariate statistics at the UFZ, Leipzig, Germany, a course on in vitro and in vivo assays of endocrine disrupting chemicals using fish models at INERIS, Verneuil-en-Halatte, France, and a course focusing on chemical screening, prioritization of environmental pollutants and data storage in European databases in the Jasna Valley, Slovakia. In total, ten specialized courses complemented by local scientific and soft skill training courses provide a comprehensive supplement to the scientific work in a traditional $\mathrm{PhD}$ thesis. An additional component of the training program involves 1 - to 3-month secondments (at least one secondment per fellow) hosted by EDA-EMERGE partner institutes to work on aspects of the $\mathrm{PhD}$ research where the host institute possesses specialized expertise in analytical techniques or data analysis not typically associated with the home institute. The advantages of the secondment initiative is that, in addition to the specialized skills and expert training acquired, the fellows also broaden their professional network and obtain a different research or working perspective.

\section{Discussion}

Within the context of EDA-EMERGE research goals, a number of scientific work packages are being implemented such as developing novel bio-analytical tools, novel chemical tools, hyphenated tools, a higher-tier EDA study, establishing a simplified protocol, and conducting,

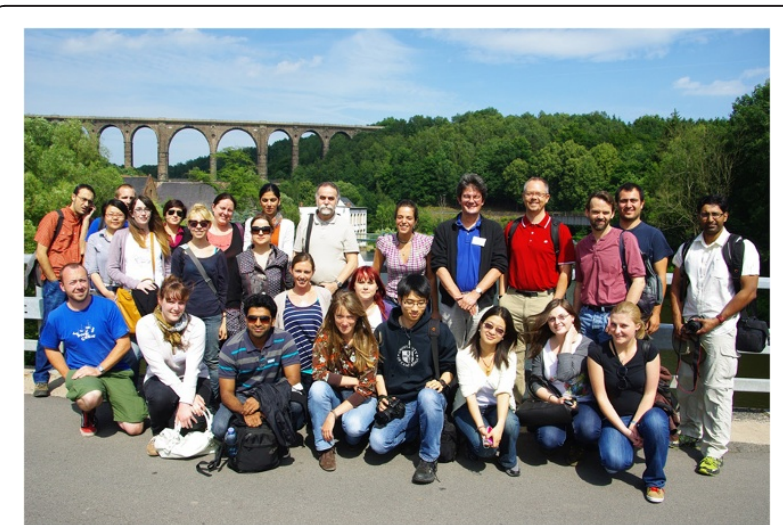

Figure 4 EDA-EMERGE fellows and lecturers. They were in front of the viaduct in Göhren, Germany bridging the valley of the Zwickauer Mulde River. Completed in 1871 and still in operation, it is one of the most impressive bridges in Germany demonstrating early railway architecture monitoring, and sampling within the European Demonstration Programme (EDP). Bio-analytical methods being developed include mechanism-specific screening tools in early life stages of zebrafish, novel fish-based biological tools, and fluorescing vertebrate models for EDA of endocrine disrupting chemicals. DNA microarray fingerprints, a proteomics and a metabolomics approach to direct EDA, are also in progress, linking multiple contaminations with multiple toxicological end points. A particular emphasis is given to toxicogenomic tools including proteomics and metabolomics to achieve unbiased effect detection. These innovative biological tools are supplemented with sophisticated chemical tools for fractionation and structure elucidation. Extensive separation and characterization of contaminants are achieved with novel fractionation tools. Comprehensive multidimensional GC/MS is used for both identification and quantitative screening. Since the identification of polar toxicants is still one of the big bottlenecks of EDA; a specific focus is given to structure elucidation techniques using LC-MS/MS. This will be achieved by developing integrated analytical and computer tools for structure elucidation of polar compounds, including the development of new approaches for retention and fragmentation prediction, diagnostic derivatization techniques, as well as metabolite prediction and identification in treatment processes in the water cycle. Innovative automated high-throughput EDA approaches are in development that directly link fractionation, biotesting, and identification. This includes twodimensional microfractionation approaches prior to effect detection and chemical analysis.

Beyond these method developments within the individual $\mathrm{PhD}$ projects, there are also integrated activities in the scientific work packages focused on a simplified protocol that will be applied in the EDP. This will provide the $\mathrm{PhD}$ fellows with experience in planning and implementing large, collaborative, EU-wide sampling campaigns. Standard operational procedures are in development for all steps of the simplified protocol including an integrated large-volume fractionated in situ solid phase extraction, a large set of bioassays, and chemical screening analysis for about 300 potentially relevant compounds. The EDP is being performed by $\mathrm{PhD}$ pairs (biology and analytical chemistry) from different partner institutions with complementary expertise. Each pair selected a river basin as well as relevant sampling sites representing specific pollution situations and sources and typically including a reference site as well as one integrative sampling site related to monitoring (e.g., the Watch List Study sampling sites).

The fellows have been trained in all relevant techniques such as chemical structure elucidation, chemometrics, sampling/extraction, biotesting, and chemical analysis. The training courses and personalized career development 
plans were designed after a baseline study was performed using an initial training needs analysis survey sent to all EDA-EMERGE fellows at the outset of the project. These specialized technical and scientific training courses together with secondments at partner institutes were supplemented by soft-skill courses such as presentation skills and a film/media course in conjunction with standard local courses such as scientific writing, language skills, and time management offered at most host institutes. According to a basic EDA-EMERGE dissemination plan, ESR fellows have been encouraged from the outset to disseminate their research output via online open-source forums, conferences, and journal publications.

\section{Conclusions}

In response to the call to train a new generation of young scientists in the interdisciplinary skills related to EDA and the management of European water sources, EDA-EMERGE provides a highly systematic and comprehensive research and training program within a consortium that brings together key competences from universities, research centers, private companies, and regulatory authorities. A balanced mix of 14 fellows from biology and analytical chemistry backgrounds were linked by research work packages focused on novel analytical tool development. Applications in a simplified protocol and an EDP provided an ideal basis for specialized training and structured public dissemination of the results. Networking is achieved via a range of activities from opening training course participation to external fellows and external experts, a summer school, conference presentations, dissemination and outreach activities as Marie Curie ambassadors, and interaction with other networks to secondments with EDA-EMERGE partners and associated partners.

\section{Competing interests}

The authors declare that they have no competing interests.

\section{Authors' contributions}

WB was responsible for the general design of the project and wrote the first draft of the manuscript. The other authors - SG, TS, MK, MH, MM, JH, KS, JS, $A H$, JS, ZR, SAA, MS, MC, ML, PL, ST, XO, MS, KT, ACdA, JF, MHW, MA, SK, HH, TBS, CDP, AT, and PS - contributed with specific information concerning their respective methods. All authors helped revise the draft of the manuscript. All authors read and approved the final manuscript.

\section{Acknowledgments \\ The EDA-EMERGE project is supported by the EU Seventh Framework Programme (FP7-PEOPLE-2011-ITN) under the grant agreement number 290100.}

\section{Author details}

'UFZ Department of Effect-Directed Analysis, Helmholtz Centre for Environmental Research, Permoserstr. 15, Leipzig 04318, Germany. ${ }^{2}$ Eawag, Swiss Federal Institute of Aquatic Science and Technology, Dübendorf 8600, Switzerland. ${ }^{3}$ Environmental Institute, Okruzna 784/42, Kos 97241, Slovak Republic. ${ }^{4}$ Unit of Ecotoxicology in vitro and in vivo, Institut National de I'Environnement Industriel et des Risques (INERIS), Verneuil-en-Halatte f-60550, France. ${ }^{5}$ Italian Institute of Health, 299 Viale Regina Elena, Rome
00161, Italy. ${ }^{6}$ Institute for Environmental Studies (IVM), Faculty of Earth and Life Sciences, VU University, De Boelelaan 1087, Amsterdam, HV 1081, The Netherlands. ${ }^{7}$ KWR Watercycle Research Institute, Groningenhaven 7, Nieuwegein, PE 3433, The Netherlands. ${ }^{8}$ Norwegian Institute for Water Research, Gaustadalléen 21, Oslo, NO 0349, Norway. ${ }^{9}$ Research Institute for Ecosystem Analysis and Assessment - gaiac, Kackertstr. 10, Aachen 52072, Germany. ${ }^{10}$ Rudjer Boskovic Institute, Division for Marine and Environmental Research, Bijenicka c. 54, Zagreb 10000, Croatia. ${ }^{11}$ Institute for Environmental Research, RWTH Aachen University, Worringerweg 1, Aachen 52074, Germany. ${ }^{12}$ WatchFrog S.A., 1 rue Pierre Fontaine, Evry 91000, France.

Received: 9 July 2013 Accepted: 10 July 2013

Published: 17 July 2013

\section{References}

1. Schäfer RB, Caquet T, Siimes K, Mueller R, Lagadic L, Liess M: Effects of pesticides on community structure and ecosystem functions in agricultural streams of three biogeographical regions in Europe. Sci Total Environ 2007, 382:272-285.

2. von der Ohe PC, Schmitt-Jansen M, Slobodnik J, Brack W: Triclosan - the forgotten priority substance? Environ Sci Pollut Res 2012, 19:585-591.

3. Oehlmann J, Di Benedetto P, Tillmann M, Duft M, Oetken M, SchulteOehlmann U: Endocrine disruption in prosobranch molluscs: evidence and ecological relevance. Ecotoxicology 2007, 16:29-43.

4. Sumpter JP: Protecting aquatic organisms from chemicals: the harsh realities. Philosophical Transactions of the Royal Society a-Mathematical Physical and Engineering Sciences 2009, 367:3877-3894.

5. Von der Ohe PC, Dulio V, Slobodnik J, De Deckere E, Kühne R, Ebert RU, Ginebreda A, de Coomann W, Schüürmann G, Brack W: A new risk assessment approach for the prioritization of 500 classical and emerging organic microcontaminants as potential river basin specific pollutants under the European water framework directive. Sci Total Environ 2011, 409:2064-2077.

6. European Commission: Directive 2000/60/EC of the European Parliament and of the Council establishing a framework for the Community action in the field of water policy. Brussels: European Commission; 2000.

7. Daughton CG: "Emerging" chemicals as pollutants in the environment: a 21st century perspective. Renewable Resources Journal 2005, 23:6-23.

8. Brack W, Apitz SE, Borchardt D, Brils J, Cardoso AC, Foekema EM, van Gils J, Jansen S, Harris B, Hein M, Heise S, Hellsten S, de Maagd PGJ, Müller D, Panov VE, Posthuma L, Quevauviller P, Verdonschot PFM, von der Ohe PC: Toward a holistic and risk-based management of European river basins. Integr Environ Assess Manag 2009, 5:5-10.

9. Hein M, de Deckere E, de Zwart D, Foekema EM, Marcomini A, Munoz I, Posthuma L, Rotter S, Sabater S, Schmitt C, Schmitt-Jansen M, Segner H, Semenzin E, van Gils J, van Hattum B, van Vliet LA, von der Ohe P, Brack W: MODELKEY key findings and recommendations for reaching EU Water Framework Directive's quality objectives. Umweltwissenschaften und Schadstoff-Forschung 2010, 22:217-228.

10. Krauss $M$, Singer $H$, Hollender J: LC-high resolution MS in environmental analysis: from target screening to the identification of unknowns. Anal Bioanal Chem 2010, 397:943-951.

11. Brack W: Effect-directed analysis: a promising tool for the identification of organic toxicants in complex mixtures. Anal Bioanal Chem 2003, 377:397-407.

12. Hewitt $L M$, Marvin $C H$ : Analytical methods in environmental effectsdirected investigations of effluents. Mutat Res Rev Mutat Res 2005, 589:208-232.

13. Burgess RM, Ho KT, Brack W, Lamoree M: Effects directed analysis (EDA) and toxicity identification evaluation (TIE): complementary but different approaches for diagnosing causes of environmental toxicity. Enviromental Toxicology and Chemistry. in press.

14. Legler J, van Velzen M, Cenijn PH, Houtman CJ, Lamoree MH, Wegener JW: Effect-directed analysis of municipal landfill soil reveals novel developmental toxicants in the zebrafish Danio rerio. Environ Sci Technol 2011, 45:8552-8558.

15. Thomas KV, Langford K, Petersen K, Smith AJ, Tollefsen KE: Effect-directed identification of naphthenic acids as important in vitro xeno-estrogens and anti-androgens in North sea offshore produced water discharges. Environ Sci Technol 2009, 43:8066-8071. 
16. Brack W: Effect-Directed Analysis of Complex Environmental Contamination. Heidelberg: Springer; 2011.

17. Brack W, Dulio V, Slobodnik J: The NORMAN network and its activities on emerging environmental substances with a focus on effect-directed analysis of complex environmental contamination. Environ Sci Eur 2012, 24:29.

18. Kosmehl T, Hallare AV, Reifferscheid G, Manz W, Braunbeck T, Hollert H: A novel contact assay for testing genotoxicity of chemicals and whole sediments in zebrafish embryos. Environ Toxicol Chem 2006, 25:2097-2106.

19. Vosges $M$, Le Page $Y$, Chung B-C, Combarnous $Y$, Porcher J-M, Kah O, Brion F: 17a-Ethinylestradiol disrupts the ontogeny of the forebrain GnRH system and the expression of brain aromatase during early development of zebrafish. Aquat Toxicol 2010, 99:479-491.

20. Brion F, Le Page Y, Piccini B, Cardoso O, Tong SK, Chung BC, Kah O: Screening estrogenic activities of chemicals or mixtures in vivo using transgenic (cyp19a1b-GFP) zebrafish embryos. PLoS One 2012, 7(5):e36069.

21. Meland S, Farmen E, Heier LS, Rosseland BO, Salbu B, Song Y, Tollefsen KE: Hepatic gene expression profile in brown trout (Salmo trutta) exposed to traffic related contaminants. Sci Total Environ 2011, 409:1430-1443.

22. Kosmehl T, Otte JC, Yang L, Legradi J, Bluhm K, Zinsmeister C, Keiter SH, Reifferscheid G, Manz W, Braunbeck T, Straehle U, Hollert H: A combined DNA-microarray and mechanism-specific toxicity approach with zebrafish embryos to investigate the pollution of river sediments. Reprod Toxicol 2012, 33:245-253

23. Groh KJ, Nesatyy VJ, Segner H, Eggen RIL, Suter MJF: Global proteomics analysis of testis and ovary in adult zebrafish (Danio rerio). Fish Physiology and Biochemistry 2011, 37:619-647.

24. Schriks M, van Leerdam JA, van der Linden SC, van der Burg B, van Wezel $A P$, de Voogt P: High-resolution mass spectrometric identification and quantification of glucocorticoid compounds in various wastewaters in The Netherlands. Environ Sci Technol 2010, 44:4766-4774.

25. Senta I, Krizman I, Ahel M, Terzic S: Integrated procedure for multiresidue analysis of dissolved and particulate drugs in municipal wastewater by liquid chromatography-tandem mass spectrometry. Anal Bioanal Chem 2013, 405:3255-3268.

26. Huntscha S, Singer HP, McArdell CS, Frank CE, Hollender J: Multiresidue analysis of 88 polar organic micropollutants in ground, surface and wastewater using online mixed-bed multilayer solid-phase extraction coupled to high performance liquid chromatography-tandem mass spectrometry. Journal of Chromatography A 2012, 1268:74-83.

27. Ulrich $N$, Schuurmann $G$, Brack W: Linear solvation energy relationships as classifiers in non-target analysis - a capillary liquid chromatography approach. Journal of Chromatography A 2011, 1218:8192-8196.

28. Schymanski EL, Gallampois CMJ, Krauss M, Meringer M, Neumann S, Schulze T, Wolf S, Brack W: Consensus structure elucidation combining GC/El-MS, structure generation, and calculated properties. Anal Chem 2012, 84:3287-3295

29. Schulze T, Schymanski E, Stravs M, Neumann S, Krauss M, Singer H, Hug C, Gallampois C, Hollender J, Slobodnik J, Brack W, NORMAN MassBank: Towards a community-driven, open-access accurate mass spectral database for the identification of emerging pollutants. In NORMAN Bulletin. issue 3rd edition. Kos: NORMAN Association; 2012:9-10.

30. Kool J, Heus F, de Kloe G, Lingeman H, Smit AB, Leurs R, Edink E, de Esch IJP, Irth $H$, Niessen WMA: High-resolution bioactivity profiling of mixtures toward the acetylcholine binding protein using a nanofractionation spotter technology. J Biomol Screen 2011, 16:917-924.

doi:10.1186/2190-4715-25-18

Cite this article as: Brack et al: EDA-EMERGE: an FP7 initial training network to equip the next generation of young scientists with the skills to address the complexity of environmental contamination with emerging pollutants. Environmental Sciences Europe 2013 25:18.

\section{Submit your manuscript to a SpringerOpen ${ }^{\circ}$ journal and benefit from:}

- Convenient online submission

- Rigorous peer review

- Immediate publication on acceptance

- Open access: articles freely available online

- High visibility within the field

- Retaining the copyright to your article

Submit your next manuscript at $>$ springeropen.com 